\title{
Public knowledge and beliefs about dementia risk reduction: a national survey of Australians
}

Ben J Smith ${ }^{*}$, Suha Ali and Henry Quach ${ }^{1}$

\begin{abstract}
Background: With the dramatically increasing contribution of Alzheimer's Disease and other forms of dementia to the global burden of disease, countries are being urged to address this as a public health priority. This study investigated whether Australian adults recognise this as an important health issue, and hold beliefs and knowledge that are consistent with recommendations concerning dementia risk reduction. This research was undertaken to guide national brain health awareness and education strategies.

Methods: A cross-sectional telephone survey was undertaken of 1,003 Australians aged 20-75 years. This measured the importance placed on dementia, beliefs and confidence related to risk reduction, knowledge of risk reduction methods, and the perceived age-relevance of these. In analysis the data were stratified by sex, age, educational attainment, household income, language preference and previous exposure to dementia. Multivariable logistic regression was undertaken to identify variables independently associated with beliefs and knowledge.
\end{abstract}

Results: People aged 60 years and over identified dementia as very important (17.2\%) more often than those aged 40-59 years (5.1\%) or 20-39 years (2.1\%). While $41.5 \%$ of respondents believed the risk of dementia could be reduced, $26.9 \%$ were very confident that they could achieve this. Mental activity (57.1\%) was identified as beneficial much more often than physical activity (31.3\%), healthy eating (23.3\%) and other cardiovascular health behaviours. Women, people of English-speaking origin, and those having contact with a person with dementia, showed better knowledge of several health behaviours.

Conclusions: Growing attention is being given to population risk reduction to combat the dramatic increase in the burden of disease due to dementia. In Australia many people do not yet hold beliefs and knowledge that support this, which highlights the need for concerted awareness raising that dementia is not an inevitable aspect of ageing, and for education about the role of vascular health in dementia risk reduction.

Keywords: Dementia, Cognitive health, Health behaviours, Health promotion

\section{Background}

Alzheimer's disease and other forms of dementia are among the most rapidly increasing threats to public health globally. In 2012 the Global Burden of Disease Project reported that over the two decades from 1990 until 2010 the total disability adjusted life years due to Alzheimer's disease and other forms of dementia had risen by $99.3 \%$ [1], an increase of $53.3 \%$ per 100,000 persons. Over this period the age standardised death rate due to these conditions was estimated to have risen by $95.4 \%$ [2]. Such dramatic rises have been driven by population aging and the

\footnotetext{
* Correspondence: ben.smith@monash.edu

'School of Public Health and Preventive Medicine, Monash University, Lev 3, 89 Commercial Rd, Melbourne 3004, Australia

Full list of author information is available at the end of the article
}

epidemiological transition that is underway in many low and middle income countries [3].

Countries in Western Europe, North America and the developed region of the Western Pacific have been identified as having the highest prevalence of dementia [4]. In Australia, dementia was ranked as the third leading cause of death in 2010 and the fourth highest contributor to the total burden of disease in 2011 [5]. It is projected that the number Australians with some form of dementia will triple by the year 2050 [5]. Similar projections have been made for the United States [6], the United Kingdom [7] and nations across Europe [8].

As a result of the marked increase in the burden of disease due to dementia the World Health Organisation 
has called for nations to place this issue on their public health agendas. Raising awareness and reducing stigma, improving dementia care and services, and providing support for caregivers are important areas of action [9]. There is also growing support for a proactive approach, to reduce the incidence and delay the onset of dementia through health promotion efforts directed at whole populations [10-12].

Current evidence concerning the aetiology of Alzheimer's disease and dementia indicates that, apart from age and genetic characteristics, there are potentially modifiable biomedical, behavioural, psychological and social factors associated with disease risk. Biomedical factors that are consistently recognised are diabetes, hypertension, hyperlipidaemia and obesity $[13,14]$. Smoking, physical activity, dietary intake and levels of alcohol consumption are behaviours that are related to dementia risk $[15,16]$. Psychological and social factors that have been reported to be associated with age-related cognitive decline are depression, cognitive activity and social contact $[17,18]$. Recent epidemiological studies which have reported a decline in the prevalence of dementia among the elderly, compared with earlier cohorts, suggest that reductions in risk factors at the population level and improvements in standards of living and health care can lower the burden of disease due to this condition $[19,20]$.

Determining the relative contribution of the risk factors to different forms of dementia is a research priority and the role of some factors (e.g., alcohol intake), and their interaction with genetic characteristics, is still being explored [21]. Notwithstanding this, the global increases in the Alzheimer's Disease and dementia, and the observed associations with modifiable factors has prompted researchers and advocates to recommend that population level risk reduction strategies be instigated by government and non-government agencies [22]. A growing number of organisations are heeding this call, demonstrated by initiatives such as the Healthy Brain Initiative in the US [23], the Your Brain Matters campaign in Australia [24], the National Memory Programme in Finland [25] and the Forget Me Not education program in Ireland [26]. This arena of activity has brought with it a need for new evidence, about the prevailing knowledge, beliefs and behaviours concerning dementia and the potential to maintain cognitive health among different population segments [27].

Studies of public knowledge and beliefs towards Alzheimer's disease and other forms of dementia have focused predominantly upon perceived severity and personal susceptibility to these diseases, and understanding of symptoms and treatment [28-32]. A review of research about public perceptions of cognitive health in the US found that 3 of 10 studies examined beliefs about lifestyle and brain health, or the potential to reduce the risk of dementia [33]. Of these, the Brain Health Poll undertaken by the
American Society on Ageing and Metlife Foundation [34] was the most extensive, investigating beliefs about whether brain health could be improved and the actions that were believed to beneficial for this purpose. A more recent national survey in Australia [35] investigated similar questions, with a focus upon dementia risk reduction rather than brain health improvement. Other studies have been undertaken with selected population groups (e.g., older people, carers), used convenience samples, and measured knowledge of a narrower range of risk factors [36-39].

With leading authorities advocating for a public health approach towards dementia there is a need to monitor the extent to which populations have also adopted this perspective. Up-to-date data is required about public knowledge and beliefs, including the importance placed on dementia, the potential for risk reduction, the perceived age-groups for whom this is relevant, the behaviours that should be undertaken, and confidence that these will produce beneficial outcomes. This purpose of the study reported here was to investigate these factors among a crosssection of Australian adults, to determine the prevalence of risk reduction knowledge and beliefs and differences between socio-demographic groups. The longer term objective of this research was to inform the design and targeting of national brain health initiatives.

\section{Methods}

\section{Study population and sampling}

An Australia-wide sample of persons aged 20-75 years was recruited. Participants were required to speak English and not be affected by a mental impairment that reduced their ability to answer the survey questions.

Sampling was undertaken using random digit dialling, by a social research organisation with extensive experience in epidemiological and population studies. Because of the growing number of persons who use a cell phone in preference to a land line, a dual sampling frame was developed that comprised $70 \%$ landline numbers and $30 \%$ cell phone numbers. In order to improve representativeness, when households were contacted a request was made to speak with the individual who had the next birthday.

Ethical approval for the conduct of the study was given by the Monash University Human Research Ethics Committee (approval no. CF12/2427-2012001309).

\section{Procedures}

Surveys were conducted by trained interviewers over three weeks, from August to September 2012. In order to determine eligibility and complete recruitment, up to six calls were made to establish contact and a further four to achieve completed interviews. The length of surveys was approximately 10 minutes. 


\section{Measures}

To investigate knowledge and beliefs related to dementia, straightforward questions with good face and content validity were used, several of which have been used in previous population studies. In order to measure the personal importance that respondents placed upon dementia as a health issue, the questions used in the US Brain Health Poll [34] were adopted. These were two openended questions which asked respondents to nominate the first and second health issues that it is most important for them to have information about.

Several questions, which had been used in previous surveys commissioned by Alzheimer's Australia [40], were asked to determine whether respondents believed that the risk of developing dementia could be reduced, and their knowledge of the behaviours that are beneficial for risk reduction. The first of these measures required individuals to respond, using a 5-point Likert scale, to the question: "Thinking now about dementia, which has many causes including Alzheimer's disease, please tell me if you personally agree or disagree that it is possible to reduce the risk of a person developing dementia". Following this an open-ended question was asked: "As far as you are aware, what do you think a person can do to help reduce the risk of developing Alzheimer's disease or another form of dementia?". Up to five responses were elicited by means of prompting.

To determine when respondents believed it is beneficial to commence action to reduce dementia, they were asked: "At what age do you think people should start to take action to reduce their risk of Alzheimer's disease or another form of dementia?" A list of age ranges ( $<18$ years, 18-29 years etc.) were provided to choose from. In order to measure their personal confidence that they can take action to reduce their own risk of dementia respondents were asked: "How would you rate your confidence that you can take action now that will reduce your risk of Alzheimer's disease or another form of dementia?" A fourpoint rating scale was given, ranging from very confident, to not confident at all.

The demographic information collected included gender, age, education level, household income and language spoken at home. Respondents were also asked if they had ever had personal contact with a person with dementia.

\section{Statistical analysis}

The sample was weighted to the age and gender distribution of the Australian population. In bivariate analysis, the Chi-squared statistic was used to compare dementia beliefs and knowledge between different strata of respondents. The independent variables in these analyses were: gender; age group (20-39 years, 40-59 years, 60-75 years); educational attainment (up to year 10, high school or technical college, University); yearly household income (less than $\$ 40,000, \$ 40,000-\$ 99,000, \$ 100,000$ and over); language spoken at home (English, other), and; prior contact with a person with dementia (yes, no). Backwards step-wise logistic regression modelling was undertaken, including those variables where bivariate relationships were observed, to identify those independently associated with dementia beliefs and knowledge. A maximum P-value of 0.1 was adopted to determine retention of variables at each step of modelling. Analyses were carried out using SPSS V19.0.

\section{Results}

\section{Respondent characteristics}

In total 1,003 interviews were carried out with a cooperation rate, among eligible persons contacted, of $58 \%$. The characteristics of the respondents are shown in Table 1. The mean age was 47.6 years (SD 18.44) and most were aged in the 40-59 year age group (39.1\%). A higher proportion of respondents were women (57.1\%). Just over $40 \%$ were educated at the university level and the majority were in full-time or part-time work (64.6\%). Income

Table 1 Characteristics of survey respondents

\begin{tabular}{|c|c|c|}
\hline Characteristics & Unweighted & Weighted \\
\hline Mean age (SD) & $47.6(18.44)$ & $46.2(18.27)$ \\
\hline \multicolumn{3}{|l|}{ Age groups } \\
\hline $20-39$ yrs & 299 (30.1\%) & $382(38.3 \%)$ \\
\hline $40-59$ yrs & $397(39.9 \%)$ & $352(35.3 \%)$ \\
\hline $60+$ year & $298(30.0 \%)$ & $263(26.4 \%)$ \\
\hline \multicolumn{3}{|l|}{ Sex } \\
\hline Men & $429(42.9 \%)$ & $491(49.1 \%)$ \\
\hline Women & $571(57.1 \%)$ & 509 (50.9\%) \\
\hline \multicolumn{3}{|l|}{ Education level* } \\
\hline Completed up to year 10 & $214(21.6 \%)$ & $202(20.6 \%)$ \\
\hline Completed year $12 / \mathrm{TAFE}$ & $373(37.7 \%)$ & $369(37.5 \%)$ \\
\hline Completed University & $402(40.2 \%)$ & $413(42 \%)$ \\
\hline \multicolumn{3}{|l|}{ Work status } \\
\hline Full time/Part time work & $643(64.6 \%)$ & $645(64.9 \%)$ \\
\hline Not working & $352(35.4 \%)$ & $349(35.1 \%)$ \\
\hline \multicolumn{3}{|l|}{ Income groups } \\
\hline Up to $\$ 39,999$ & $245(29.6 \%)$ & $265(31.8 \%)$ \\
\hline$\$ 40,000$ to $\$ 99,999$ & $334(40.4 \%)$ & $319(38.4 \%)$ \\
\hline$\$ 100,000$ or more & $248(30.0 \%)$ & $248(29.8 \%)$ \\
\hline \multicolumn{3}{|l|}{ Language } \\
\hline English & $850(85.3 \%)$ & $839(84.3 \%)$ \\
\hline Other & $146(14.7 \%)$ & $156(15.7 \%)$ \\
\hline \multicolumn{3}{|l|}{ Contact with dementia } \\
\hline Yes & $730(73 \%)$ & $713(71.3 \%)$ \\
\hline No & $270(27 \%)$ & $287(28.7 \%)$ \\
\hline
\end{tabular}

*14 people did not respond, so total percent is less than 100. 
groups were evenly spread between those earning $\$ 100,000$ or more (30.0\%), those earning less than $\$ 40,000$ (29.6\%), and those in the middle income range (40.4\%). Just under $15 \%$ of respondents spoke a language other than English at home, and almost three-quarters reported prior contact with a person suffering from Alzheimer's disease or other forms of dementia.

Table 1 shows the unweighted characteristics of respondents in the completed survey, and the profile of the sample after weighting to the sex and age distribution of the Australian population.

\section{Prevalence of knowledge and beliefs about dementia risk reduction}

As shown in Table 2, 7.2\% of survey respondents rated dementia as one of the two most important health issues of concern for them, which made it the sixth ranked condition after heart disease, stress, obesity, diabetes and prostate cancer. Overall, a higher proportion of women than men $(9.0 \%$ vs $5.3 \%)$ rated dementia as of high importance to them. Table 2 shows that respondents aged 60 years and over ranked dementia as the third most important issue ( $17.2 \%$ nominated it), whereas among those aged $40-59$ years it was ranked eighth (5.2\%), and for those aged $20-39$ years it ranked fifteenth (2.2\%).

Table 3 shows that $41.5 \%$ of respondents strongly believed that the risk of dementia could be reduced, while just over one-quarter $(26.9 \%)$ were very confident that they could take action to lower their personal risk of dementia. A lower proportion of women than men strongly agreed that the risk can be reduced, while a higher proportion of those with prior contact with a person with dementia held this belief compared with those who reported no prior contact. Most respondents believed that action to reduce dementia risk should commence before the age of 40 years; but there was a lower proportion of persons aged 60 years and over who held this belief compared to the younger age groups. Persons with a university level education and those in the lowest income bracket most frequently reported that efforts to lower dementia risk should begin before the age of 40 years.

The action that respondents most often identified as valuable for lowering dementia risk was mental activity, which was followed in levels of recognition by physical activity, a healthy diet, and social activity (Table 4 ). Moderate alcohol consumption and non-smoking were least frequently identified as beneficial for dementia prevention.

Women more frequently identified mental activity, social activity and a healthy diet as beneficial for dementia risk reduction than men. Respondents aged 60 years and over most often reported that mental activity and social activity are beneficial, whereas the highest proportion who recognised moderate alcohol consumption as beneficial were aged 20-39 years. Those with a university level education most often reported that social activity is beneficial for dementia risk reduction, and those in the highest income bracket most often recognised the value of moderate alcohol consumption. A higher proportion of respondents who spoke English at home recognised the value of mental activity, physical activity and a healthy diet. Respondents with prior contact with a person suffering from dementia also more frequently reported that these three behaviours are beneficial, and that social activity can assist in risk reduction.

\section{Multivariable analysis of factors associated with dementia beliefs and knowledge}

Table 5 shows that although women were more likely than men to consider dementia to be a personal health priority (adjusted odds ratio (OR) 1.88, 95\% confidence interval (CI), 1.07-3.31), they were less likely to believe that the risk of dementia could be reduced or to express confidence that they could achieve this outcome for themselves. Respondents aged 60 years and over were significantly more likely to consider dementia to be a very important health issue (OR 14.17, 95\% CI 5.67-35.39) than those in the youngest age group, but were less likely to believe that risk reduction should start before the age of 40 years. Table 5 also shows that those from households in the top income category had the lowest adjusted odds of believing that risk reduction action should start in early adulthood, and those who have had contact with a person suffering from dementia had the highest odds of believing that the risk of dementia can be reduced.

Women were more likely than men to report knowledge of the value of mental activity, social activity and a

Table 2 Most important health issues identified by respondents, by age group, with ranking of dementia relative to others

\begin{tabular}{|c|c|c|c|c|c|c|c|c|}
\hline Rank & Total & $\%$ & $18-39$ years & $\%$ & 40-59 years & $\%$ & $60+$ years & $\%$ \\
\hline 1 & Heart disease & 22.5 & Obesity & 19.3 & Heart disease & 28.9 & Heart disease & 32.0 \\
\hline 2 & Stress & 22.5 & Heart disease & 10.4 & Stress & 28.9 & Stress & 32.0 \\
\hline 3 & Obesity & 11.5 & Stress & 10.4 & Diabetes & 11.2 & Dementia & 17.2 \\
\hline 4 & Diabetes & 9.3 & Alcohol & 8.1 & Prostate cancer & 11.2 & Arthritis & 13.6 \\
\hline \multirow[t]{2}{*}{5} & Prostate cancer & 9.0 & Skin cancer & 8.0 & Breast cancer & 10.5 & Diabetes & 10.5 \\
\hline & Dementia $(6)^{*}$ & 7.2 & Dementia $(15)^{*}$ & 2.2 & Dementia $(8)^{*}$ & 5.2 & & \\
\hline
\end{tabular}

*Ranking of dementia relative to other issues. 
Table 3 Beliefs about the reduction of dementia risk

\begin{tabular}{|c|c|c|c|c|c|}
\hline & Demer & Juction & & groups for & \\
\hline & Strongly agree & Very confident & $<40$ yrs & $40-59$ yrs & $60+y r s$ \\
\hline Total & 41.5 & 26.9 & 57.1 & 37.6 & 5.4 \\
\hline Sex & & & & & \\
\hline Men & $46.0^{* *}$ & $30.7^{* *}$ & 57.2 & 37.8 & 5.0 \\
\hline Women & $37.0^{* *}$ & $23.3^{* *}$ & 56.9 & 37.3 & 5.8 \\
\hline Age group & & & & & \\
\hline $20-39$ yrs & 42.0 & 27.2 & $65.7^{* * *}$ & $32.7^{* * *}$ & $1.6^{* * *}$ \\
\hline 40-59 yrs & 39.6 & 23.5 & $56.3^{* * *}$ & $39.0^{* * *}$ & $4.6^{* * *}$ \\
\hline $60+y r s$ & 42.9 & 30.8 & $44.4^{* * *}$ & $43.2^{* * *}$ & $12.4^{* * *}$ \\
\hline Education & & & & & \\
\hline$\leq$ year 10 & 43.8 & 26.7 & $52.2^{*}$ & $40.9^{*}$ & $7.0^{*}$ \\
\hline High School/TAFE & 40.9 & 26.2 & $56.7^{*}$ & $35.7^{*}$ & $7.6^{*}$ \\
\hline University & 41.1 & 26.8 & $58.8^{*}$ & $38.4^{*}$ & $2.8^{*}$ \\
\hline Income & & & & & \\
\hline$<\$ 40 k$ & 42.9 & 28.3 & $58.5^{*}$ & $34.4^{*}$ & $7.1^{*}$ \\
\hline$\$ 40-99 k$ & 38.8 & 23.5 & $55.1^{*}$ & $42.2^{*}$ & $2.6^{*}$ \\
\hline$\$ 100+$ & 43.9 & 23.4 & $53.4^{*}$ & $43.1^{*}$ & $3.4^{*}$ \\
\hline Language & & & & & \\
\hline English & 41.5 & 26.2 & 56.9 & 37.8 & 5.3 \\
\hline Other & 41.0 & 30.8 & 57.0 & 37.6 & 5.4 \\
\hline Contact with dement & & & & & \\
\hline Yes & $44.1^{*}$ & 27.0 & 57.2 & 37.9 & 4.9 \\
\hline No & $34.6^{*}$ & 26.6 & 56.7 & 36.7 & 6.5 \\
\hline
\end{tabular}

Chi-squared - *p $<0.05 ;{ }^{* *} p<0.01 ;{ }^{* * *} \mathrm{p}<0.001$.

healthy diet for dementia risk reduction (Table 6). Those aged 60 years had a significantly higher adjusted odds of recognising the benefits of social activity, but the lowest odds of identifying non-smoking (OR 0.28, 95\% CI 0.090.91 ) as a beneficial action. Persons educated at the university level were more likely to recognise the benefits of being socially active for dementia risk reduction, compared to those educated up to the Year 10 level, and people in the middle and highest categories of household income were most likely to identify moderate alcohol consumption as beneficial. English speaking respondents had higher adjusted odds of identifying mental activity and a healthy diet as beneficial for risk reduction than those who spoke a language other than English. Persons who reported past contact with someone suffering from dementia were more likely to recognise the benefits of mental activity, physical activity and a healthy diet, compared with those who did not have this prior contact.

\section{Discussion}

This study has found that many Australians do not recognise dementia as a health priority, and that there is limited understanding of the potential to reduce the risk of this condition through a range of lifestyle behaviours, particularly around mid-life. This indicates that there is great scope to increase awareness that dementia is not an inevitable part of ageing and that, similar to a number of vascular health conditions, the risk of this can be reduced through health promotion action.

Overall, just $7 \%$ of respondents rated dementia as one of the top two issues that are important for them to receive information about, which was the same as the proportion of people who nominated "brain health" related conditions as one of their top two issues in the US Brain Health Poll in 2006 [34]. The present study found marked age differences in the perceptions of the importance of dementia, with those aged 60 years and over showing the highest prevalence of concern about this condition. Recent population surveys in other countries, notably France [41] and Israel [42], have reported similar findings that worry and fear of Alzheimer's disease is significantly higher among older respondents.

Of particular concern is that only $5 \%$ of those aged 40-59 years rated dementia as very important, even though they are nearing a stage of life when the risk of the condition increases dramatically and studies show mid-life 
Table 4 Knowledge of behaviours that are beneficial for dementia risk reduction

\begin{tabular}{|c|c|c|c|c|c|c|}
\hline & Mental activity & Social activity & Physical activity & Healthy diet & Moderate alcohol & Non-smoking \\
\hline Total & 57.1 & 12.1 & 31.3 & 23.3 & 5.1 & 3.1 \\
\hline \multicolumn{7}{|l|}{ Sex } \\
\hline Men & $51.5^{* *}$ & $8.9^{* *}$ & 29.9 & $18.9^{* *}$ & 6.3 & 3.5 \\
\hline Women & $62.4^{* *}$ & $15.3^{* *}$ & 32.6 & $27.5^{* *}$ & 3.9 & 2.8 \\
\hline \multicolumn{7}{|l|}{ Age group } \\
\hline $20-39$ yrs & $51.3^{*}$ & $8.1^{* *}$ & 27.7 & 22.8 & $6.6^{* *}$ & 4.5 \\
\hline $40-59$ yrs & $59.9^{*}$ & $12.2^{* *}$ & 31.5 & 26.7 & $6.5^{* *}$ & 2.8 \\
\hline $60+y r s$ & $61.5^{*}$ & $17.9^{* *}$ & 36.5 & 19.8 & $0.8^{* *}$ & 1.1 \\
\hline \multicolumn{7}{|l|}{ Education } \\
\hline$\leq$ year 10 & 57.4 & $11.3^{* *}$ & 34.7 & 18.8 & 3.0 & 1.5 \\
\hline High School/TAFE & 57.5 & $8.4^{* *}$ & 28.7 & 24.1 & 4.7 & 3.0 \\
\hline University & 58.1 & $16.2^{* *}$ & 32.7 & 25.7 & 6.1 & 4.1 \\
\hline \multicolumn{7}{|l|}{ Income } \\
\hline$<\$ 40 k$ & 53.6 & 11.3 & 35.1 & 23.0 & $1.1^{*}$ & 1.1 \\
\hline$\$ 40-99 k$ & 58.8 & 12.5 & 31.7 & 23.4 & $5.9^{*}$ & 3.8 \\
\hline$\$ 100+$ & 63.7 & 10.9 & 28.2 & 27.4 & $6.9^{*}$ & 3.6 \\
\hline \multicolumn{7}{|l|}{ Language } \\
\hline English & $60.7^{* * *}$ & 12.2 & $32.7^{*}$ & $25.3^{* *}$ & 5.5 & 3.0 \\
\hline Other & $37.8^{* * *}$ & 12.8 & $23.7^{*}$ & $14.1^{* *}$ & 3.2 & 3.8 \\
\hline \multicolumn{7}{|l|}{ Contact with dementia } \\
\hline Yes & $61.9^{* * *}$ & $13.4^{*}$ & $33.9^{* *}$ & $26.3^{* * *}$ & 4.8 & 3.4 \\
\hline No & $45.1^{* * *}$ & $8.7^{*}$ & $24.7^{* *}$ & $16.0^{* * *}$ & 5.9 & 2.4 \\
\hline
\end{tabular}

Chi-squared - * $p<0.05 ;{ }^{* *} p<0.01 ;{ }^{* * *} p<0.001$.

Table 5 Demographic and social factors independently associated with risk reduction beliefs

\begin{tabular}{|c|c|c|c|c|c|c|c|c|}
\hline & \multicolumn{2}{|c|}{$\begin{array}{l}\text { Dementia rated as } \\
\text { important }\end{array}$} & \multicolumn{2}{|c|}{$\begin{array}{l}\text { Believe risk can be } \\
\text { reduced }\end{array}$} & \multicolumn{2}{|c|}{$\begin{array}{l}\text { Very confident can } \\
\text { lower risk }\end{array}$} & \multicolumn{2}{|c|}{$\begin{array}{l}\text { Believe action should } \\
\text { start at }<40 \text { yrs }\end{array}$} \\
\hline & Adj OR & $95 \% \mathrm{Cl}$ & Adj OR & $95 \% \mathrm{Cl}$ & Adj OR & $95 \% \mathrm{Cl}$ & Adj OR & $95 \% \mathrm{Cl}$ \\
\hline \multicolumn{9}{|l|}{ Sex } \\
\hline \multicolumn{9}{|l|}{ Men (ref) } \\
\hline Women & 1.88 & $1.07-3.31$ & 0.69 & $0.53-0.90$ & 0.69 & $0.52-0.91$ & & \\
\hline \multicolumn{9}{|l|}{ Age } \\
\hline \multicolumn{9}{|l|}{ 20-39 (ref) } \\
\hline $40-59$ & 3.29 & $1.23-8.76$ & & & & & 0.66 & $0.48-0.92$ \\
\hline $60+$ & 14.17 & $5.67-35.39$ & & & & & 0.32 & $0.21-0.48$ \\
\hline \multicolumn{9}{|l|}{ Income } \\
\hline \multicolumn{9}{|c|}{$<\$ 40 \mathrm{k}$ (ref) } \\
\hline$\$ 40-99 k$ & & & & & & & 0.69 & $0.48-1.00$ \\
\hline$\$ 100 \mathrm{k}+$ & & & & & & & 0.58 & $0.39-0.86$ \\
\hline \multicolumn{9}{|c|}{ Contact w/-dementia } \\
\hline \multicolumn{9}{|l|}{ No (ref) } \\
\hline Yes & & & 1.51 & $1.11-2.05$ & & & & \\
\hline
\end{tabular}


Table 6 Demographic and social factors independently associated with knowledge of risk reduction behaviours

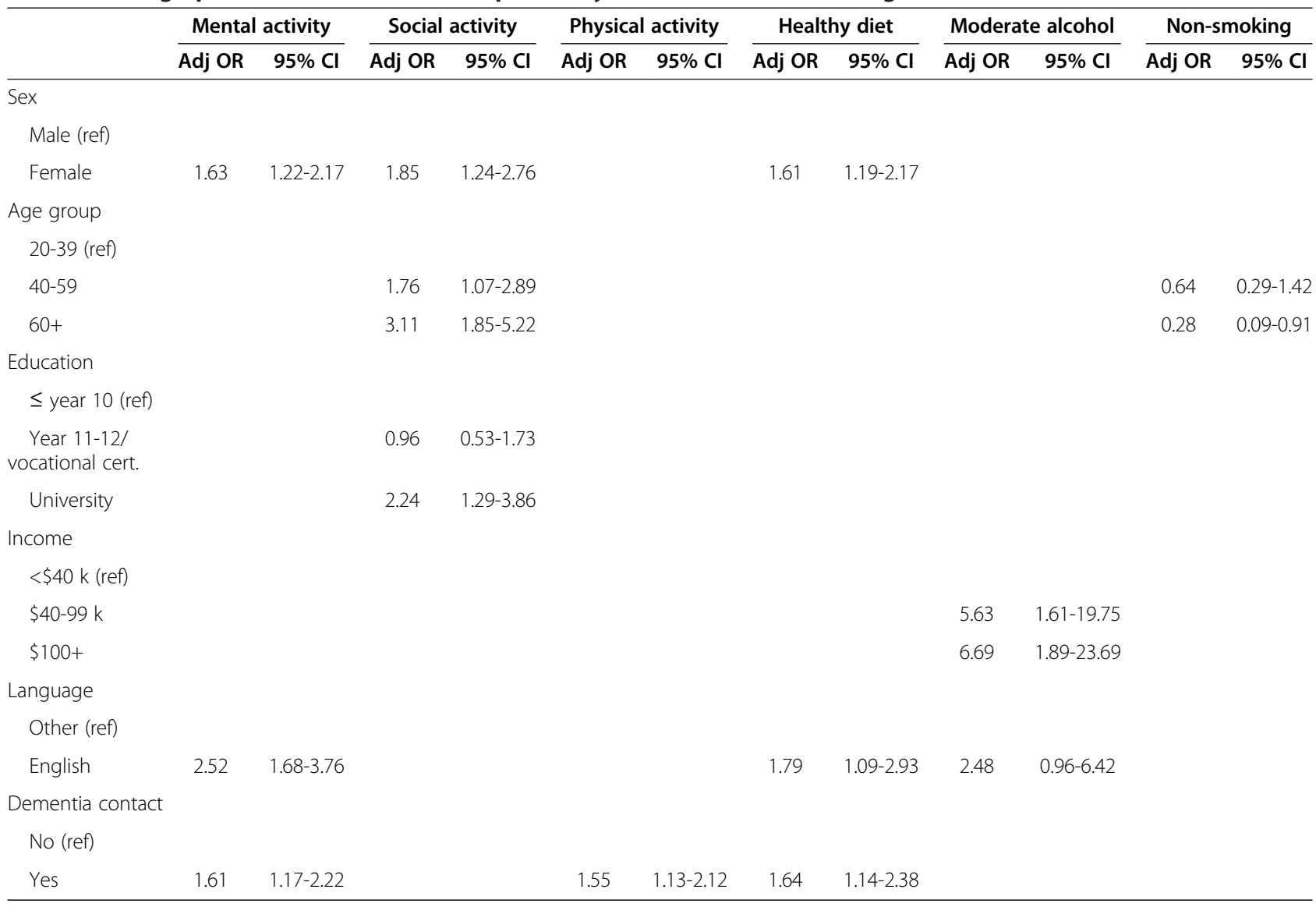

intervention can be beneficial [43,44]. It may be that this is a reflection of how middle-aged adults rate the severity of, and their personal susceptibility to, dementia relative to other conditions. It was also notable that women were more likely to rate dementia as a priority issue than men. Other researchers have postulated that gender-related patterns such as these may arise from the fact that the prevalence of dementia is higher among women than men [42]. An implication of these findings is that several important population groups may be less likely to attend to information that is disseminated about dementia because of the lower importance they place on this issue [45].

The potential for the risk of dementia to be reduced is central to the public health message about this condition, and while a substantial proportion of Australians were found to have adopted this understanding, the majority are yet to do so. This differs from previous research in Australia [35], which found that $72 \%$ of Australians believed the risk of dementia could be reduced, and of the US Brain Health Poll, where 53\% responded that there is a lot of potential to improve brain health [34]. An explanation for this is likely to be that in the present study only persons who strongly agreed that the risk of dementia could be reduced were classified as having this understanding, in order to identify those who hold views consistent with the information disseminated by government and non- government agencies.

Reporting prior contact with a person with dementia was independently related to a higher likelihood of understanding that the risk of dementia can be reduced. A plausible explanation of this is that this previous contact has lead to exposure to information about the aetiology and risks factors for this condition, which is consistent with studies which have reported that that health literacy is higher among those with greater contact with health services [46]. Unexpectedly, women were less likely than men to strongly agree that the risk of dementia can be reduced, which is inconsistent with evidence that they have a higher level of health literacy than men [47], and that they more frequently act as primary carers of person with dementia [35]. These gender differences in perceptions about risk reduction may be explained by research concerning the social construction of masculinity and its impact upon health beliefs [48], which has reported that men are socialised to portray independence and control and to deny vulnerability.

The investigation of confidence to reduce the personal risk of dementia was undertaken to determine the extent 
to which the public not only understand that risk reduction is possible, but believe that it can be successfully applied to their own lives. There was a substantially lower proportion of respondents with this high level of confidence than there was of respondents who understood that risk could be reduced and, once again, women were less likely to convey this view than men. This confidence reflects the outcome expectancies concerning action to reduce dementia risk which is recognised within social cognitive theory as a determinant of goal development and behaviour $[49,50]$. This finding, therefore, shows a low prevalence of a belief that may be a significant mediator between exposure to public health messages about dementia and personal action.

An encouraging finding was that more than half of respondents believed that efforts to reduce dementia risk should commence before 40 years of age. Respondents over 60 years of age were, however, significantly less likely than those age under 40 years to hold this belief, which may be self-affirmation of their own efforts in later life to maintain brain health. The possible reasons for the lower proportion of respondents from high income households who believed that risk reduction should commence in early adulthood are unclear. This may reflect a view among high income persons that they can draw upon clinical services to address the health problems encountered at different stages of life.

While several studies have investigated knowledge of methods to reduce dementia risk, most have used prompted, closed questions $[34,51,52]$ which may overestimate knowledge prevalence due to the possibility of correct guessing [53]. The unprompted knowledge question used here found that undertaking mentally stimulating activities was the most widely identified activity that a person could do to reduce dementia risk, which is consistent with the findings of several previous studies $[35,36,52]$. Less than one-third identified physical activity or healthy eating as beneficial, and even lower proportions recognised the role that non-smoking and moderate alcohol intake can play. This shows that there is considerable scope to increase public understanding of the benefits that can be gained for brain health from actions to protect and improve vascular health.

Population segments which showed lower levels of knowledge of several dementia risk reduction behaviours were men, people without prior contact with someone with dementia, and those from a non-English speaking background. There have been few studies which have compared knowledge of dementia risk factors and risk reduction behaviours between ethnic groups. A study in the United Kingdom [54] did not find differences in risk factor knowledge in a convenience sample of older people from south Indian background and Caucasian backgrounds. In a population survey of dementia literacy in Australia, few differences were found in knowledge of dementia risk factors between persons of Greek, Italian and Chinese backgrounds and those who were third generation Australians. Notably, knowledge of mental activity, physical activity and diet did not differ between ethnic groups. In the present study ethnicity was defined according to language preference, and did not distinguish people according to their cultural background or duration of residence in Australia. The lower levels of knowledge of several risk reduction behaviours (mental activity, diet, alcohol moderation) among non-English speaking persons indicates that public education about dementia needs to be undertaken through culturally specific, as well as mainstream media, and in languages other than English.

This study is one of few population surveys of adults across the age-spectrum investigating beliefs and knowledge concerning dementia risk reduction. In order to achieve a representative sample both landline and cell phone numbers were used in random-digit dialling, and almost $60 \%$ of those contacted consented to participate. The profile of respondents was similar to that of the Australian population in terms of age, household income and language spoken at home, however, there was an overrepresentation of people who had attained a university level qualification ( $40.2 \%$ vs $25.4 \%$ in Australia, [55]. A further limitation was that, while the survey questions had good face validity, their reliability and validity has not been evaluated.

\section{Conclusions}

The growing evidence about the association between dementia and potentially modifiable risk factors, and the significant rise in the global burden of disease due to this condition, has generated wide consensus that a population risk reduction approach must be adopted by policy makers and health promotion agencies. This national survey found, however, that the beliefs and knowledge of adult Australians about dementia are yet to support this perspective. This provides a strong case for dementia risk reduction and brain health to be given greater attention in public health education efforts, and for dementia to be given a higher profile in existing strategies to tackle physical activity, unhealthy eating and other vascular risk behaviors. The data presented here provide a baseline for the measurement of change in public beliefs and knowledge, and identify priority groups for these educational efforts, especially men, people aged less than 60 years, and those from a non-English speaking background.

\section{Competing interests}

The authors declare that they have no competing interests.

\section{Authors' contributions}

BS managed the study, conducted data analysis and prepared the manuscript. SA assisted in survey design and manuscript preparation. $\mathrm{HQ}$ conducted data analysis and reviewed the manuscript. All authors read and approved the final manuscript. 


\section{Acknowledgments}

This work was supported by the Australian Government Chronic Disease Prevention and Service Improvement Fund. The Social Research Centre, Melbourne, conducted the population sampling and telephone surveys for this study. The advice of Glenn Rees, Chief Executive Officer of Alzheimer's Australia, was helpful for the preparation of this manuscript.

\section{Author details}

${ }^{1}$ School of Public Health and Preventive Medicine, Monash University, Lev 3, 89 Commercial Rd, Melbourne 3004, Australia. ${ }^{2}$ Alzheimer's Australia (Victoria), 155 Oak Street, Parkville 3052, Australia.

Received: 8 February 2014 Accepted: 19 June 2014

Published: 28 June 2014

\section{References}

1. Murray CJ, Vos T, Lozano R, Naghavi M, Flaxman AD, Michaud C, Ezzati M, Shibuya K, Salomon JA, Abdalla S, Aboyans V, Abraham J, Ackerman I, Aggarwal R, Ahn SY, Ali MK, Alvarado M, Anderson HR, Anderson LM, Andrews KG, Atkinson C, Baddour LM, Bahalim AN, Barker-Collo S, Barrero LH, Bartels DH, Basáñez MG, Baxter A, Bell ML, Benjamin EJ, et al: Disability-adjusted life years (DALYs) for 291 diseases and injuries in 21 regions, 1990-2010: a systematic analysis for the Global Burden of Disease Study 2010. Lancet 2012, 380(9859):2197-2223.

2. Lozano R, Naghavi M, Foreman K, Lim S, Shibuya K, Aboyans V, Abraham J, Adair T, Aggarwal R, Ahn SY, Alvarado M, Anderson HR, Anderson LM, Andrews KG, Atkinson C, Baddour LM, Barker-Collo S, Bartels DH, Bell ML, Benjamin EJ, Bennett D, Bhalla K, Bikbov B, Bin Abdulhak A, Birbeck G, Blyth F, Bolliger I, Boufous S, Bucello C, Burch M, et al: Global and regional mortality from 235 causes of death for 20 age groups in 1990 and 2010: a systematic analysis for the Global Burden of Disease Study 2010. Lancet 2012, 380(9859):2095-2128.

3. Prince $M$, Bryce R, Albanese E, Wimo A, Ribeiro W, Ferri CP: The global prevalence of dementia: a systematic review and metaanalysis. Alzheimers Dement 2013, 9(1):63-75.

4. Ferri CP, Prince M, Brayne C, Brodaty H, Fratiglioni L, Ganguli M, Hall K, Hasegawa K, Hendrie $H$, Huang $Y$, Jorm A, Mathers C, Menezes PR, Rimmer E, Scazufca M: Global prevalence of dementia: a Delphi consensus study. Lancet 2005, 366(9503):2112-2117.

5. Australian Institute of Health and Welfare: Dementia in Australia. Canberra: AlHW; 2012

6. Hebert LE, Weuve J, Scherr PA, Evans DA: Alzheimer disease in the United States (2010-2050) estimated using the 2010 census. Neurology 2013, 80(19):1778-1783.

7. Knapp M, Prince M: Dementia UK: The Full Report. London: London School of Economics, King's College London and The Alzheimer's Society; 2007.

8. Commission of the European Communities: Communication from the Commission to the European Parliament and Council on a European initiative on Alzheimer's disease and other dementias. Brussels: Commission of the European Communities; 2009.

9. World Health Organisation, Alzheimer's Disease International: Dementia: A public health priority. Geneva: WHO; 2012.

10. Burke D, Hickie I, Breakspear M, Gotz J: Possibilities for the prevention and treatment of cognitive impairment and dementia. Br J Psychiatry 2007, 190:371-372.

11. Lautenschlager NT, Almeida OP, Flicker L: Preventing dementia: why we should focus on health promotion now. Int Psychogeriatr 2003, 15(2):111-119.

12. Rabins PV: Do we know enough to begin prevention interventions for dementia? Alzheimers Dement 2007, 3(2 Suppl):006.

13. Barnes DE, Yaffe $K$ : The projected effect of risk factor reduction on Alzheimer's disease prevalence. Lancet Neurol 2011, 10(9):819-828.

14. Daviglus ML, Plassman BL, Pirzada A, Bell CC, Bowen PE, Burke JR, Connolly ES Jr, Dunbar-Jacob JM, Granieri EC, McGarry K, Patel D, Trevisan M, Williams JW Jr: Risk factors and preventive interventions for Alzheimer disease: state of the science. Arch Neurol 2011, 68(9):1185-1190.

15. Anstey KJ, Mack HA, Cherbuin N: Alcohol consumption as a risk factor for dementia and cognitive decline: meta-analysis of prospective studies. Am J Geriatr Psychiatry 2009, 17(7):542-555.

16. Polidori MC, Nelles G, Pientka L: Prevention of dementia: focus on lifestyle. Int J Alzheimers Dis 2010, 29:393579.
17. Hendrie HC, Albert MS, Butters MA, Gao S, Knopman DS, Launer LJ, Yaffe K, Cuthbert BN, Edwards E, Wagster MV: The NIH Cognitive and Emotional Health Project. Report of the Critical Evaluation Study Committee. Alzheimers Dement 2006, 2(1):12-32.

18. Williams KN, Kemper S: Interventions to reduce cognitive decline in aging. J Psychosoc Nurs Ment Health Serv 2010, 48(5):42-51.

19. Christensen K, Thinggaard M, Oksuzyan A, Steenstrup T, Andersen-Ranberg K, Jeune B, McGue M, Vaupel JW: Physical and cognitive functioning of people older than 90 years: a comparison of two Danish cohorts born 10 years apart. Lancet 2013, 382(9903):1507-1513.

20. Matthews FE, Arthur A, Barnes LE, Bond J, Jagger C, Robinson L, Brayne C: A two-decade comparison of prevalence of dementia in individuals aged 65 years and older from three geographical areas of England: results of the Cognitive Function and Ageing Study I and II. Lancet 2013, 382(9902):1405-1412.

21. Panza F, Frisardi V, Seripa D, Logroscino G, Santamato A, Imbimbo BP, Scafato E, Pilotto A, Solfrizzi V: Alcohol consumption in mild cognitive impairment and dementia: harmful or neuroprotective? Int J Geriatr Psychiatry 2012, 27(12):1218-1238.

22. Yaffe K, Aisen P, Albert M, Anstey K: Dementia (Including Alzheimer's Disease) can be Prevented: Statement Supported by International Experts. J Alzheimers Dis 2014, 38:699-703.

23. Healthy Brain Initiative. http://www.cdc.gov/aging/healthybrain/

24. Your Brain Matters. http://www.yourbrainmatters.org.au/.

25. Finnish Ministry of Social Affairs and Health: National Memory Programme 2012-2020. Creating a "memory-friendly" Finland. Helsinki: Finnish Ministry of Social Affairs and Health; 2013.

26. Brain Health: Forget Me Not. http://www.alzheimer.ie/brain-health.html.

27. Centers for Disease Control and Prevention, the Alzheimer's Association: The Healthy Brain Initiative: A National Public Health Road Map to Maintaining Cognitive Health. Chicago: Alzheimer's Association; 2007

28. Arai $Y$, Arai A, Zarit SH: What do we know about dementia?: a survey on knowledge about dementia in the general public of Japan. Int J Geriatr Psychiatry 2008, 23(4):433-438.

29. Garvey G, Simmonds D, Clements V, O'Rourke P, Sullivan K, Gorman D, Curnow V, Wise S, Beattie E: Making sense of dementia: understanding amongst indigenous Australians. Int J Geriatr Psychiatry 2011, 26(6):649-656.

30. Jones RW, Mackell J, Berthet K, Knox S: Assessing attitudes and behaviours surrounding Alzheimer's disease in Europe: key findings of the Important Perspectives on Alzheimer's Care and Treatment (IMPACT) survey. J Nutr Health Aging 2010, 14(7):525-530.

31. Li X, Fang W, Su N, Liu Y, Xiao S, Xiao Z: Survey in Shanghai communities: the public awareness of and attitude towards dementia. Psychogeriatrics 2011, 11(2):83-89.

32. Rimmer E, Wojciechowska M, Stave C, Sganga A, O'Connell B: Implications of the Facing Dementia Survey for the general population, patients and caregivers across Europe. Int J Clin Pract 2005, 59:17-24.

33. Anderson LA, Day KL, Beard RL, Reed PS, Wu B: The public's perceptions about cognitive health and Alzheimer's disease among the U.S population: a national review. Gerontologist 2009, 49(1):S3-S11.

34. American Society on Ageing, Metlife Foundation: Attitudes and Awareness of Brain Health: Poll. San Francisco: American Society on Ageing; 2006.

35. Low L-F, Anstey KJ: Dementia literacy: recognition and beliefs on dementia of the Australian public. Alzheimers Dement 2009, 5(1):43-49.

36. Anderson LN, McCaul KD, Langley LK: Common-sense beliefs about the prevention of Alzheimer's disease. Aging Ment Health 2011, 15(7):922-931.

37. Carpenter BD, Zoller SM, Balsis S, Otilingam PG, Gatz M: Demographic and contextual factors related to knowledge about Alzheimer's disease. Am J Alzheimers Dis Other Demen 2011, 26(2):121-126.

38. Lee SE, Lee HY, Diwan S: What do Korean American immigrants know about Alzheimer's disease (AD)? The impact of acculturation and exposure to the disease on AD knowledge. Int J Geriatr Psychiatry 2010 25(1):66-73.

39. Yeo LHJ, Horan MA, Jones M, Pendleton N: Perceptions of risk and prevention of dementia in the healthy elderly. Dement Geriatr Cogn Disord 2007, 23(6):368-371.

40. Farrow M: Dementia risk reduction: what do Australians know? Canberra: Alzheimer's Australia; 2008.

41. Cantegreil-Kallen I, Pin S: Fear of Alzheimer's disease in the French population: impact of age and proximity to the disease. Int Psychogeriatr 2012, 24(1):108-116. 
42. Werner P, Goldberg S, Mandel S, Korczyn AD: Gender differences in lay persons' beliefs and knowledge about Alzheimer's disease (AD): a national representative study of Israeli adults. Arch Gerontol Geriatr 2013, 56(2):400-404

43. Hanon O, Forette F: Treatment of hypertension and prevention of dementia. Alzheimers Dement 2005, 1(1):30-37.

44. Laitinen MH, Ngandu T, Rovio S, Helkala EL, Uusitalo U, Vittanen M, Nissinen A, Tuomilehto J, Soininen H, Kivipelto M: Fat intake at midlife and risk of dementia and Alzheimer's disease: a population-based study. Dement Geriatr Cogn Disord 2006, 22(1):99-107.

45. Wang C, O'Neill SM, Rothrock N, Gramling R, Sen A, Acheson LS, Rubinstein WS, Nease DE Jr, Ruffin MT: Comparison of risk perceptions and beliefs across common chronic diseases. Prev Med 2009, 48(2):197-202.

46. Baker DW: The meaning and the measure of health literacy. J Gen Intern Med 2006, 21(8):878-883.

47. Kutner M, Greenberg E, Jin Y, Paulsen C: The Health Literacy of America's Adults: Results From the 2003 National Assessment of Adult Literacy. Washington, DC: U.S. Department of Education; 2006.

48. Courtenay WH: Constructions of masculinity and their influence on men's well-being: a theory of gender and health. Soc Sci Med 2000, 50(10):1385-1401.

49. Bandura A: Health promotion by social cognitive means. Health Educ Behav 2004, 31(2):143-164.

50. White SM, Wojcicki TR, MCAuley E: Social cognitive influences on physical activity behavior in middle-aged and older adults. J Gerontol B Psychol Sci Soc Sci 2012, 67(1):18-26.

51. Hudson JM, Pollux PMJ, Mistry B, Hobson S: Beliefs about Alzheimer's disease in Britain. Aging Ment Health 2012, 16(7):828-835.

52. Roberts JS, Connell CM, Cisewski D, Hipps YG, Demissie S, Green RC: Differences between African Americans and whites in their perceptions of Alzheimer disease. Alzheimer Dis Assoc Disord 2003, 17(1):19-26.

53. Aday L: Designing and conducting health surveys: a comprehensive guide. San Francisco, CA: Jossey Bass; 1996.

54. Purandare N, Luthra V, Swarbrick C, Bums A: Knowledge of dementia among South Asian (Indian) older people in Manchester UK. Int J Geriatr Psychiatry 2007, 22(8):777-781.

55. Australian Bureau of Statistics Year Book Australia, 2012 - Educational attainment. http://www.abs.gov.au/ausstats/abs@.nsf/Lookup/by\% 20Subject/1301.0 2012 Main\%20Features Educational\%20attainment 110.

doi:10.1186/1471-2458-14-661

Cite this article as: Smith et al:: Public knowledge and beliefs about dementia risk reduction: a national survey of Australians. BMC Public Health 2014 14:661.

\section{Submit your next manuscript to BioMed Central and take full advantage of:}

- Convenient online submission

- Thorough peer review

- No space constraints or color figure charges

- Immediate publication on acceptance

- Inclusion in PubMed, CAS, Scopus and Google Scholar

- Research which is freely available for redistribution 